\title{
Interdisciplinarity in Smart Sustainable City Education: Exploring Educational Offerings and Competencies Worldwide
}

\author{
Magdalena Ciesielska \\ Gdańsk University of Technology \\ magdalena.ciesielska@pg.edu.pl
}

\author{
Nina Rizun \\ Gdańsk University of Technology \\ nina.rizun@pg.edu.pl
}

\author{
Tomasz Janowski \\ Gdańsk University of Technology \\ Danube University Krems \\ tomasz.janowski@pg.edu.pl
}

\begin{abstract}
More and more higher education institutions are offering specialized study programs for current and future managers of Smart Sustainable Cities (SSCs). In the process, they try to reconcile the interdisciplinary nature of such studies, covering at least the technical and social aspects of SSC management, with their own traditionally discipline-based organization. However, there is little guidance on how such interdisciplinarity should be introduced. In order to address this gap, this paper identifies 87 SSC-related study programs from around the world and analyzes their disciplinary and interdisciplinary coverage. The analysis classifies programs and competencies, the former using text mining and clustering algorithms, the latter using Bloom's taxonomy and correlation analysis.
\end{abstract}

\section{Introduction}

Many countries around the world are currently putting digital technology at the service of urbanization and sustainability, and transforming traditional cities into Smart and Sustainable Cities (SSCs) [1]-[4]. In line with this trend, city managers have to manage technological, organizational and social innovation in public service delivery processes [5]-[8]. To this end, they employ modern methods and practices of public administration that cover changes caused by disruptive technologies to the structures, processes, management and services offered by public organizations [9], [10]. Due to their complexity and to ensure sustainable growth, SSCs require the integration of technological, urban, social, economic and environmental issues [11].

Such integration takes place within the SSC discipline, which is defined as "a collection of research methods and communication norms shared among a group of scholars (planners, engineers, architects, computer scientists, data scientists, ICT experts, etc.) with interest in city development" [12, p. 76]. The discipline requires integrating at least two approaches: technical including digital technology, engineering and data analysis [13]-[16] and non-technical including social sciences [17], management and environmental science [18]-[22]. Besides, urban sustainability calls for the use of varied academic disciplines and the application of critical and reflective thinking crossing disciplinary boundaries to deal with the SSC challenges [23]. A spectrum of disciplines is used to address problems associated with digital technology use in the transition towards sustainable urban development [23].

The training of future urban managers prompts many Higher Education Institutions (HEIs) to propose study programs able to provide a holistic understanding of the technological, urban, environmental and societal surroundings and facilitate the transition of cities into SSCs. Consequently, more and more universities are building education strategies, programs, and courses for SSCs. However, despite the growing importance of such education, there is little guidance on how to identify competencies that SSC education should target, and balance disciplinary and interdisciplinary contributions that are required to build such competencies.

In order to address this gap, this study examines four main questions: 1) What is the current educational offer of the SSC study programs around the world? 2) What are the common and diverging aspects of such programs? 3) What competencies are targeted by such programs? 4) How to structure such competencies to ease future development of the SSC study programs?

To address these questions and in line with the CBE (Competency-Based Education) approach, we identified and analyzed 87 programs, their objectives, content, duration and competencies, i.e. knowledge and skills. Uncovering the disciplinary and interdisciplinary nature of such programs was our particular interest. The classification of programs into disciplinary categories was conducted using text mining and $\mathrm{k}$-means clustering algorithms. The classification of competencies was done using Bloom's taxonomy [23], [24] supplemented by the correlation analysis. As a result, we obtained the distribution of knowledge areas and skills among the programs, as evidence of their interdisciplinarity. 
The remainder of this paper is organized as follows. Section 2 provides a theoretical background and the results of the literature analysis on SSC education. Subsequently, Section 3 describes the methodology adopted in this study, Section 4 presents the results, Section 5 conducts a discussion of these results, and Section 6 offers some conclusions.

\section{Background}

This section aims to provide a background for this study based on the relevant literature review. The background covers competency-based education (Section 2.1), education for SSCs (Section 2.2), interdisciplinarity in SSC education (Section 2.3) and summary (Section 2.4).

\subsection{Competency-Based Education}

The academic debate on education programs is primarily focused on the learning outcomes - what students need to know, what activity can demonstrate that knowledge, and what attitudes are being shaped during the education process. The learning outcomes are the basis for the CBE approach, the outcome-oriented learning measured by the student's demonstration of the competencies achieved rather than by the number of contact hours between teachers and students. In this paper, CBE helps develop standardized study programs on SSCs. The term "competency" has many definitions: a combination of knowledge, skills, attitudes and behaviors [25], [26], "an underlying characteristic of a person which results in effective and/or superior performance in a job" [27, p. 97] or "a functionally linked complex of knowledge, skills, and attitudes that enable successful task performance solving" [28], [29]. In this paper, we adopt the last definition.

Among educational theories, Bloom's taxonomy [24], [25] stands out as a widely recognized model for learning outcomes. According to the taxonomy [25], learning can be cognitive, affective or psychomotor. This study addresses the cognitive domain only, which includes knowledge and intellectual skills. The domain consists of six categories of skills [25]: 1) remembering - the ability to remember facts, methods and models; 2) understanding - the ability to explain and interpret concepts, terms and definitions, and to compare them based on remembered information; 3) applying - the ability to use the information to solve known problems by choosing defined solutions; 4) analyzing - the ability to recognize and relate information to solve problems; 5) evaluating - the ability to assess information according to given criteria, and create own criteria; and 6) creating - the ability to identify and match various elements to create new information and solve problems.

\subsection{Education for SSCs}

The majority of the explored research that analyses SSC study programs and their competencies focus on education for sustainability [30]-[34] or are oriented on analyzing individual bachelor's or master's programs [31], [35]. However, such research rarely touches upon the smartness dimension [36], which is the cornerstone of SSCs. According to UNESCO [37, p. 9], education for sustainable development: converges the Sustainable Development agendas; addresses the environmental, societal and economic dimensions of sustainability; increases stakeholder and local engagement; promotes the whole-institution approach; engages formal, nonformal and informal education; is interdisciplinary; uses a variety of pedagogical and activating methods. This observation is in line with [30], [35], [36], [38].

The literature identifies several competencies required to lead SSC implementations, such as: making visionary and strategic decisions; performing sectoral planning and securing resources; managing the SSC ecosystem; designing and executing SSC projects in this ecosystem; and designing, implementing and managing technical systems that run SSC operations [9], [10], [27], [39]. However, the absence of a universal approach to curriculum formulation encourages the development of a common basis in the sustainability field that should be reflected in the teaching content [31], [32].

Attempts to systematize the SSC scientific area to inform future SSC practice resulted in the identification of the following key topics to teach [20], [23], [33], [40]: systems thinking education, urban analytics, situation modelling, in-depth understanding of the urban and environmental sustainability, and monitoring and planning for SSCs. Citizen education is also crucial for stakeholder engagement to support sustainable urban change [41]. Cognitive and non-cognitive competencies for sustainability, among others, are investigated in [19], [34], [42], [43], while [44] describes the evaluation of university programs to work with smart city services.

\subsection{Interdisciplinary in SSC education}

Interdisciplinarity means a discipline located between and among many other disciplines and "closely linked to them" [45]. This concept naturally arises when attempting to solve complex problems. Interdisciplinary ways of working integrate different solutions and modes of working [46], [47]. Located at the intersection of several subject areas, interdisciplinary training creates the "third space" where meeting different perspectives causes co-construction of learning [48], [49]. This space is often realized in overarching thematic areas such as sustainability, urban planning, big data analytics, etc., where different disciplines meet to create joint complex 
solutions, products, or explanations of the world [50]. Modern interdisciplinary education should reflect the knowledge and practice accepted in the professional world and concrete specializations in particular [51]. In this professional world, most parameters are unknown, apart from a toolbox of problem-solving methods.

The creation of interdisciplinary programs also involves building flexible and adaptive skills and competencies that consider the complex nature of the tasks. A framework of interdisciplinary competencies, where each competency complements and is based on others, and where the boundaries between competencies are overlapping and blurred, is offered in [38]. The framework consists of three types of competencies [52]: 1) analytical, such as structuring problems, strategic choice and critical thinking; 2) technical, such as technological, environmental, spatial, economic and design skills; and 3) socio-political, such as conflict resolution, negotiation and communication. In order to support the formation of these competencies, attention should be paid to the importance of interaction between theory and practice as a source of empirical data and insights [53], and to experimental learning [52], [54].

\section{Methodology}

This section aims to describe the research methodology adopted in the current study. The section presents research questions in Section 3.1, the selection method of the SSC study programs in Section 3.2, and how the selected programs were analyzed in Section 3.3.

\subsection{Research questions}

This paper aims to understand the nature of interdisciplinarity in existing SSC study programs from around the world, and to develop recommendations on how such programs should introduce interdisciplinarity. To this end, we adopted five research questions to guide this study: R1) What are the SSC study programs? R2) What fields of study are the SSC study programs covering? R3) What competencies (knowledge and skills) characterize each cluster of the SSC study programs? R4) How are the SSC competencies grouped into categories? R5) How to determine the nature of the interdisciplinarity of the SSC study programs?

\subsection{Program selection}

The search for the SSC study programs was informed by previous research of the study programs within the emerging sustainability field [24]. Two sets of search criteria were used. First, we defined the keywords that characterize two dimensions of SSC: sustainability - environmental, social, economic and institutional [31] and smartness - mobility, living, environment, economy and governance [32]. These keywords were searched in the titles and descriptions of the programs. Second, we defined the keywords that characterize program levels. Three levels were targeted: a supplementary level where the learners improve their knowledge and skills through, e.g. Massive Open Online Courses; a proficiency (or bachelor degree) level where the learners acquire knowledge and skills and show reliable performance in applying them; and a mastery (or master degree) level where the learners learn to perform the acquired skills intuitively [33].

Having selected the programs for inclusion in the study, we compiled a database with information derived from their web pages: title, objectives, description, host, skill progression, languages, duration, prerequisites, competencies, classes and modules. By the term "program" we refer to university degree programs at the bachelor or master level, consisting of several modules and classes, lasting 6-6.5 or 1-2 semesters respectively. By the term "course" we refer to short term (4-8 weeks) programs, mostly online, providing course completion certificates. In the paper, we also use the term "study programs" that combines both of these concepts.

\subsection{Program analysis}

The analysis of the identified study programs was carried out in six stages described as follows.

First, to determine what fields of study the study programs are covering, we performed clustering. To this end, we applied text pre-processing, Latent Semantic Analysis, Cosine similarity, Elbow and Gap Statistic Methods and the k-means clustering algorithms to the program titles. To expand the analysis, three experts iteratively reviewed and refined the results against program objectives, descriptions and modules. As a result, six SSC study programs clusters were identified.

Second, to align knowledge areas contained in the program descriptions with the cognitive levels of Bloom's taxonomy, we carried out two steps. In the first step, text mining using the POS Tagger and n-grams search for the verbs "know" and "understand" (the first two levels of the Bloom's taxonomy) were applied to program descriptions. In the second step, by contextual coding through an iterative review, three experts extracted additional knowledge areas. We excluded the knowledge areas that appeared in a cluster only once. As a result, 27 knowledge areas were encoded.

Third, the experts grouped the knowledge areas into categories, producing four knowledge area types.

Fourth, the procedure in the second step was reapplied to the verbs "apply", "analyze", "evaluate" 
and "create" which represent the next four levels of the Bloom's taxonomy. As a result, 44 skills were encoded.

Fifth, all obtained skills were grouped into four categories using experts' evaluation.

Sixth, in-depth statistical analysis was conducted of the study program structures to reveal the presence of patterns; for instance, the distribution of knowledge areas and skills across program clusters.

\section{Results}

This section aims at presenting the main results of this study. The results include the analysis of the SSC study programs (Section 4.1), the clusters of the SSC study programs (Section 4.2) and the competencies developed by such programs (Section 4.3).

\subsection{SSC study programs}

This section provides an answer to the research question R1: What are the SSC study programs?

In total, we identified 20 courses and 67 programs - 9 bachelor and 58 master from Europe (51 programs and 6 courses), North America (6 programs and 5 courses), Asia (4 programs and 3 courses), South Africa (2 programs), Australia (4 programs), and six online courses delivered via EdX, Coursera, and MOOCs. We only assessed the courses lasting for at least 4 weeks, 100 hours, one semester. The full list of the analyzed programs is part of the supplementary material ${ }^{1}$.

\subsection{SSC study programs clusters}

This section answers the question R2: What fields of study are the SSC study programs covering?

We identified six clusters to represent such fields of study: 1) Sustainability Management, 2) Sustainable Urban Development, 3) Environmental Engineering, 4) Data-Driven and Smart Cities, 5) Urban Design, and 6) Sustainable Cities. Each cluster covers specific, nonrepetitive content and contains study programs at three levels: supplementary, bachelor and master. Table 1 present the fields of study, in the form of word clouds, for all six clusters. The clusters are described as follows, covering content, levels and objectives:

1) Sustainability Management. Content: economic, social and environmental sustainability; sustainability management through Corporate Social Responsibility; policy development and evaluation for Sustainable Development Goals; sustainable innovation. Levels: $69 \%$ master programs, $19 \%$ bachelor programs, $12 \%$ courses. Objectives: to equip students with the competencies required in the Smart City ecosystem, including managing change across the environmental, social and governance dimensions.

2) Sustainable Urban Development. Content: planning and practical skills to create more livable, sustainable and equitable cities; understanding of multidisciplinary expertise of the social and technical issues related to urban problems. Levels: $50 \%$ master programs, $31 \%$ bachelor programs and $19 \%$ courses. Objectives: to equip students with the competencies to address various issues related to urban development.

3) Urban Systems Engineering. Content: nontechnical aspects of planning, designing, realizing and maintaining urban systems; the latest technology use to develop smart urban solutions; knowledge of electrical and electronic engineering, telecommunication and computer and software engineering with a focus on renewable resources, power grids, mobility systems, and sustainable urban development. Levels: $78 \%$ master programs, $5 \%$ bachelor programs, $17 \%$ courses. Objectives: to teach competencies covering problems and technical aspects of sustainable urban systems, and tools for modelling and optimization of urban systems to achieve sustainability and economic efficiency.

4) Data-Driven and Smart Cities. Content: urban analytics, design, smart city, urban infrastructures and safety; data analysis techniques of large-scale temporal data such as GPS vehicular data, mobile phone data, social network data, etc.; ethics and justice concerning privacy and equitable access to data. Levels: $67 \%$ master programs, $6 \%$ bachelor programs, $27 \%$ courses. Objectives: to teach students technological and socioeconomic approaches to urban challenges and how digital technology and particularly the Internet of Things help utilize legacy infrastructure and services.

5) Urban Design. Content: designing sustainable and resilient cities; running urban development projects focused on environmental sustainability. Levels: $83 \%$ master programs, $8 \%$ bachelor programs, $9 \%$ courses. Objectives: to equip students with competencies to design - model, visualize, image, and map - urban solutions in their historical and socioeconomic contexts.

6) Sustainable Cities. Content: sustainable cities; energy, transport, water, waste and other systems; designing sustainable urban communities; developing integrated solutions for economic, environmental and social problems. Levels: $44 \%$ master programs and $56 \%$ courses. Objectives: to understand urban challenges, including poverty, unemployment, housing, energy systems and transport networks, and how to use digital technologies to build sustainable cities.

1 Smart Sustainable Cities Study Programs 
Table 1. Fields of study of the SSC study programs clusters

\begin{tabular}{|c|c|c|}
\hline 1) Sustainability Management & 2) Sustainable Urban Development & 3) Urban Systems Engineering \\
\hline 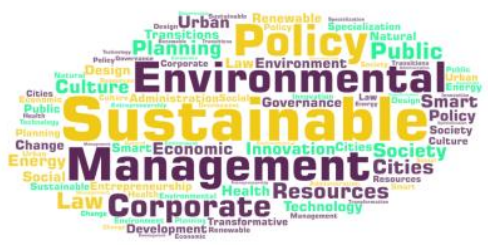 & 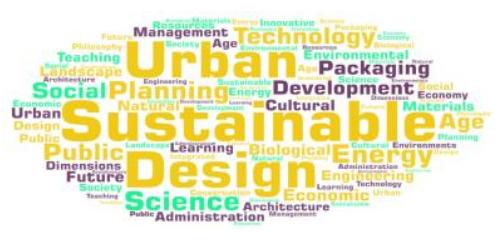 & 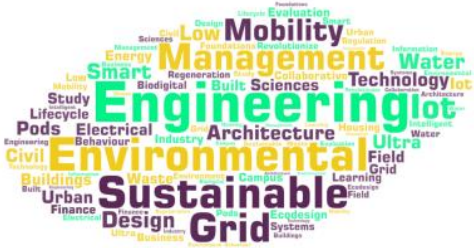 \\
\hline 4) Data-Driven and Smart Cities & 5) Urban Design & 6) Sustainable Cities \\
\hline 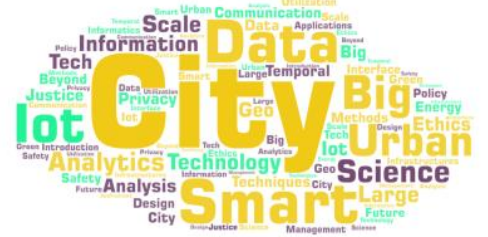 & 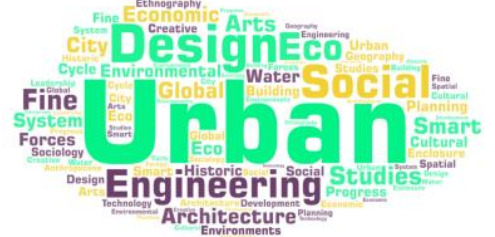 & 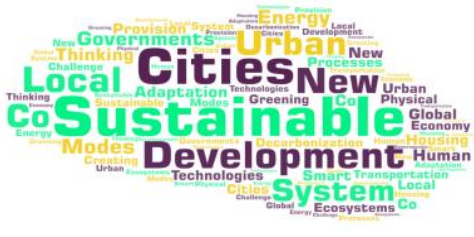 \\
\hline
\end{tabular}

\subsection{SSC study program competencies}

This section answers the research questions R3 and R4: What competencies (knowledge and skills) characterize each cluster of the SSC study programs? How are the SSC competencies grouped into categories?

Not all program descriptions contained information about both knowledge and skills. We identified 55 programs (34 master, 7 bachelor and 14 courses) with information about knowledge and 48 (43 master and 5 bachelor) with information about skills. In total, we identified 43 knowledge areas at the remembering and understanding levels, of which 27 were core.

Table 2 presents the core knowledge areas, grouped into competency categories based on similarly: 1) Governance and Urban Transformation covers public administration, management, law and urban development; 2) Innovation and Urban Systems covers social science disciplines such as smart city systems, architecture and innovation; 3) Sustainability covers social, economic and environmental sustainability, smart city ecosystem, and citizen engagement; and 4) Technology and Urban Analytics covers digital technology, statistics and mathematics. All categories, except the last one, are built upon the competencies delivered by $76-84 \%$ of the study programs. This confirms that the categories are interdisciplinary.

In total, we identified 68 unique SSC skills. The most frequent of them were assigned to the categories in Table 2. Table 3 provides an overview of such skills and their cognitive levels. The title of each skill is formed by combining the cognitive verb and the object of cognition, e.g. combining "apply" and "business strategy" produces "apply business strategy".
The distribution of skills among the analyzed study programs is: $31 \%$ analyze skills, $34 \%$ apply skills, $21 \%$ create skills, and $14 \%$ evaluate skills. The programs most focused on the apply skills are contained in the Sustainability Management and Sustainable Urban Development clusters, at $47 \%$ and $56 \%$ respectively. The most balanced distribution of skills appears in the Urban Systems Engineering cluster, at 22.5\% apply, 22,5\% create, $25 \%$ evaluate, and $30 \%$ analyze. The skills in the Sustainable Cities cluster include apply at $40 \%$ and analyze at $43 \%$, while the Data-Driven and Smart Cities cluster concentrates on the analyze skills at $42 \%$.

Table 2. SSC knowledge area categories

\begin{tabular}{|l|l|l|l|}
\hline \multicolumn{2}{|l|}{ Category } & Knowledge areas & $\%$ \\
\hline GUT & $\begin{array}{l}\text { Governance and } \\
\text { Urban } \\
\text { Transformation }\end{array}$ & $\begin{array}{l}\text { project management, transition } \\
\text { management, urban } \\
\text { development, cultural context, } \\
\text { improvements in urban living }\end{array}$ & 76 \\
\hline IUS & $\begin{array}{l}\text { Innovation and } \\
\text { Urban Systems }\end{array}$ & $\begin{array}{l}\text { planning, policy design, } \\
\text { technology, architecture, urban } \\
\text { energy systems, urban } \\
\text { infrastructure systems, urban } \\
\text { mobility systems, urban water } \\
\text { management }\end{array}$ & 84 \\
\hline S & Sustainability & $\begin{array}{l}\text { co-creation, political context, } \\
\text { responsive city, sustainable city, } \\
\text { urban resilience, economic, } \\
\text { environmental, and social } \\
\text { sustainability }\end{array}$ & 78 \\
\hline TUA & Technology and & $\begin{array}{l}\text { cybersecurity, disruptive } \\
\text { Urban Analytics } \\
\text { technology, industry 4.0, } \\
\text { graphic design, urban analytics }\end{array}$ & 19 \\
\hline
\end{tabular}


Table 3. SSC skill categories

\begin{tabular}{|c|c|c|c|c|c|}
\hline \multirow{3}{*}{ 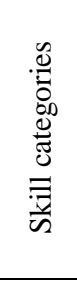 } & \multicolumn{5}{|c|}{ Assigned Skills } \\
\hline & \multicolumn{4}{|c|}{ Cognitive levels } & \multirow[b]{2}{*}{ Object of cognition } \\
\hline & $\frac{\lambda}{\frac{2}{2}}$ & 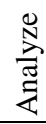 & 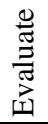 & 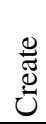 & \\
\hline \multirow{10}{*}{ 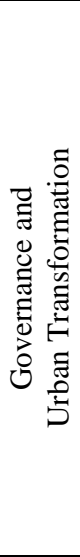 } & $\mathrm{x}$ & $\mathrm{x}$ & $\mathrm{x}$ & $\mathrm{x}$ & $\begin{array}{l}\text { business strategy, } \\
\text { urban development }\end{array}$ \\
\hline & $\mathrm{x}$ & & & & operations and management \\
\hline & $\mathrm{x}$ & & $\mathrm{x}$ & & $\begin{array}{l}\text { sustainability and social } \\
\text { marketing, sustainable supply } \\
\text { chain management, project } \\
\text { management }\end{array}$ \\
\hline & $\mathrm{x}$ & & $\mathrm{x}$ & $\mathrm{x}$ & entrepreneurship, consultancy \\
\hline & $\mathrm{x}$ & $\mathrm{x}$ & $\mathrm{x}$ & & $\begin{array}{l}\text { governance, transition } \\
\text { management }\end{array}$ \\
\hline & & $\mathrm{x}$ & & $\mathrm{x}$ & city strategy \\
\hline & & $\mathrm{x}$ & $\mathrm{x}$ & & institutions, ethics \\
\hline & $\mathrm{x}$ & $\mathrm{x}$ & & & citizens needs \\
\hline & $\mathrm{x}$ & $\mathrm{x}$ & & $\mathrm{x}$ & improvements in urban living \\
\hline & & $\mathrm{x}$ & & & cultural context \\
\hline \multirow{5}{*}{ 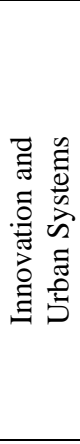 } & $\mathrm{x}$ & & & $\mathrm{x}$ & design innovation \\
\hline & $\mathrm{x}$ & $\mathrm{x}$ & $\mathrm{x}$ & $\mathrm{x}$ & $\begin{array}{l}\text { planning innovation, policy } \\
\text { innovation, urban energy } \\
\text { systems, urban water } \\
\text { management, urban waste } \\
\text { management, environmental } \\
\text { sustainability, sustainable city, } \\
\text { social sustainability } \\
\end{array}$ \\
\hline & $\mathrm{x}$ & $\mathrm{x}$ & & $\mathrm{x}$ & technology innovation \\
\hline & $\mathrm{x}$ & $\mathrm{x}$ & & $\mathrm{x}$ & $\begin{array}{l}\text { urban infrastructure systems, } \\
\text { urban mobility systems }\end{array}$ \\
\hline & & $\mathrm{x}$ & & $\mathrm{x}$ & smart urban systems \\
\hline \multirow{6}{*}{ 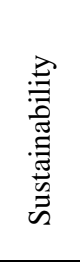 } & $\mathrm{x}$ & $\mathrm{x}$ & $\mathrm{x}$ & & socio-economic context \\
\hline & $\mathrm{x}$ & $\mathrm{x}$ & $\mathrm{x}$ & $\mathrm{x}$ & $\begin{array}{l}\text { co-creation, economic } \\
\text { sustainability }\end{array}$ \\
\hline & $\mathrm{x}$ & & & $\mathrm{x}$ & renewable products \& services \\
\hline & $\mathrm{x}$ & $\mathrm{x}$ & & & health sustainable \\
\hline & & $\mathrm{x}$ & & $\mathrm{x}$ & architecture \\
\hline & & $\mathrm{x}$ & & & political context \\
\hline \multirow{4}{*}{ 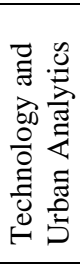 } & $\mathrm{x}$ & $\mathrm{x}$ & & & $\begin{array}{l}\text { modelling, spatial analysis \& } \\
\text { cartographic visualization }\end{array}$ \\
\hline & $\mathrm{x}$ & $\mathrm{x}$ & $\mathrm{x}$ & & $\begin{array}{l}\text { big data, urban data, } \\
\text { urban analytics, } \\
\text { statistics \& analytical tools }\end{array}$ \\
\hline & $\mathrm{x}$ & & $\mathrm{x}$ & & programming \\
\hline & $\mathrm{x}$ & $\mathrm{x}$ & & & Mathematics \\
\hline
\end{tabular}

Figure 1 demonstrates the main differences in the coverage of knowledge and skills by different SSC clusters, namely: 1) the study programs that require the most knowledge areas are in the Data-Driven and Smart Cities cluster; 2) the most balanced programs in terms of skills and knowledge are in the Sustainable Cities cluster; 3) other clusters are skill-oriented, they have between two and three times more skills than they cover the knowledge areas.

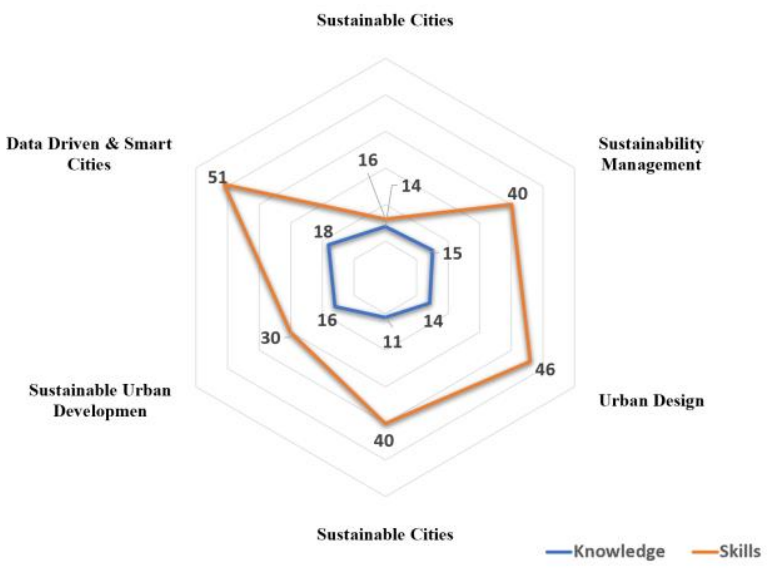

Figure 1. Coverage of the knowledge areas and skills by the SSC study program clusters

We now answer the research question R5: How to determine the nature of interdisciplinarity of the SSC study programs? To this end, we determine the distribution of the categories of competencies across the program clusters. The correlation coefficients calculated between the categories is depicted in Figure 2. The analysis uncovered two trends in the nature of the distribution across the categories.

First, it is possible to simultaneously reduce the requirements to build knowledge in the Sustainability category and increase requirements to build knowledge in the Technology and Urban Analytics category. The correlation coefficients between the Sustainability category and the Technology and Urban Analytics category is equal to -0.85 at the 0.01 significance level.

Second, it is possible to simultaneously reduce the requirements to build skills in the Sustainability category and increase the requirements to build skills in the Governance and Urban Transformation category and the Technology and Urban Analytics category. The correlation coefficients between Sustainability and Governance and Urban Transformation is -0.96, and between Sustainability and Technology and Urban Analytics is -0.82 at the 0.01 significance level.

Besides, Figure 3 depicts the distribution of the competency categories across the SSC study program clusters, providing evidence of the interdisciplinary nature of the programs. The figure demonstrates that the categories are closely linked to each other, intended to build specific sets of the SSC competencies. 
Figure 2. Correction coefficients between competency categories among the SSC study programs

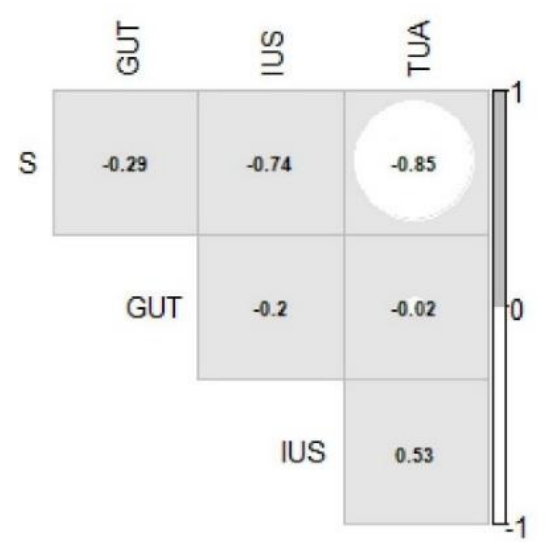

Knowledge areas

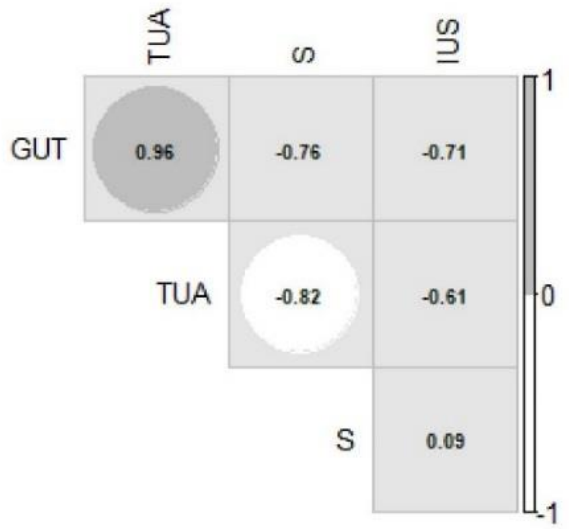

Skills

Legend: Sustainability (S), Governance and Urban Transformation (GUT), Innovation and Urban Systems (IUS), Technology and Urban Analytics (TUA)

Figure 3. Distribution of the competency categories across the SSC program clusters
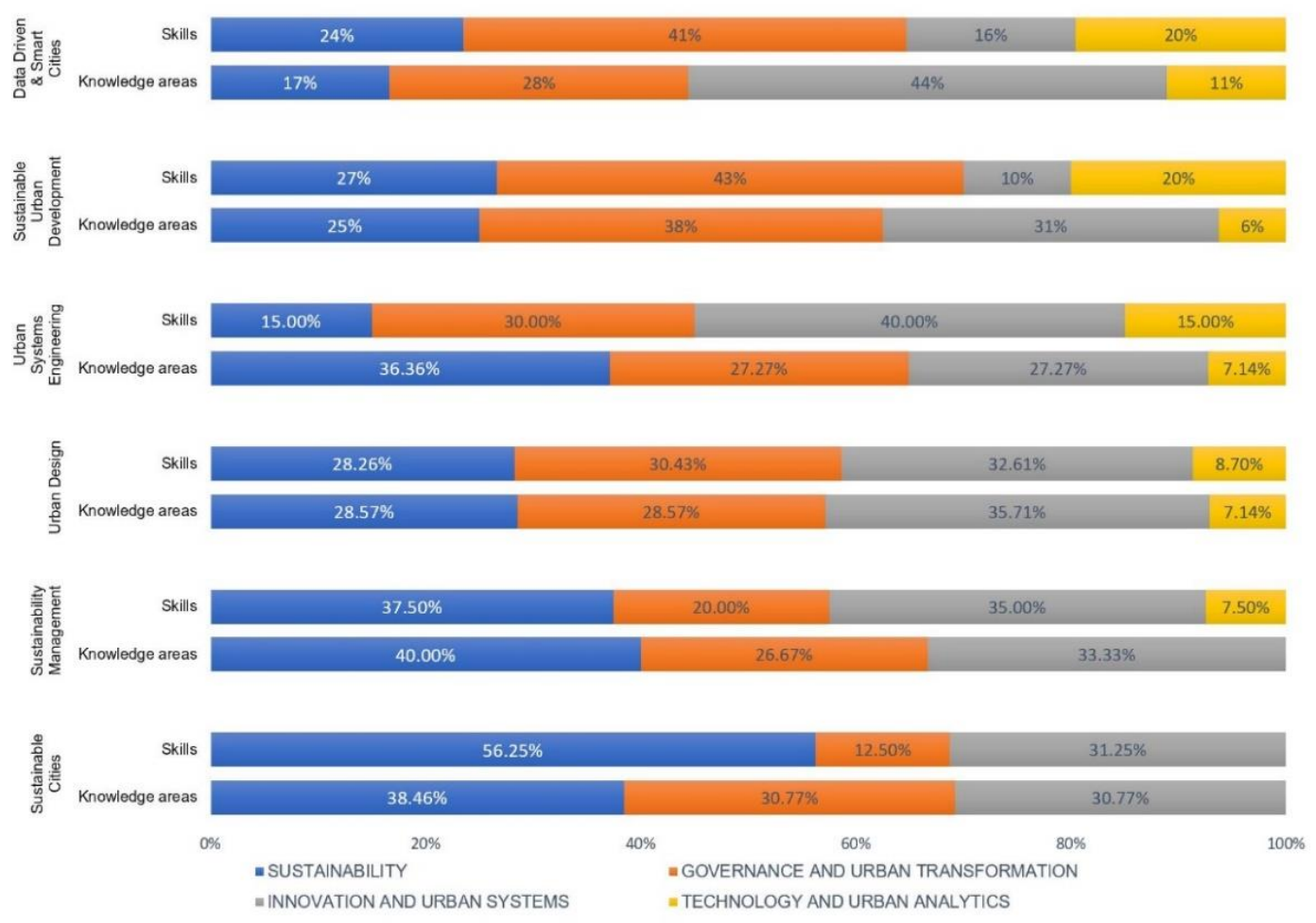

\section{Discussion}

Creating an SSC study program demands flexibility since it is associated with the use of transversal competencies (knowledge and skills) across disciplines. Therefore, selected issues from different disciplines are combined within such programs into different knowledge areas. As the SSC study programs are interdisciplinary, the key is the integration of various perspectives related to SSC. Furthermore, the integration of methods, techniques and theories relevant to different disciplines need to occur. In this context, we wish to discuss three further points highlighted by the findings of this study. 
First, the findings reveal how the students of the SSC study programs should be able to transcend disciplinary boundaries, perceive SSC problems, and develop expertise on possible solutions and their consequences. These findings fall in line with [25], [35], [37] that support a "blended" approach toward the development of master courses, drawing from the richness and diversity of available content. Our study also revealed that the analyzed programs promote diverse learning environments that cover different dimensions of sustainability, exceed boundaries and involve learners in applying digital tools and methods of data analysis to smart urban development. The interaction with city and business administrators also equips students with the skills to act as change agents.

Second, in contrast to [33], our study adopts an interdisciplinary approach from the outset, searching for study programs related both to smartness and sustainability. With this approach, we are confident that our analysis reflects the essence of SSCs, and the results obtained cover the interdisciplinary structure of the SSC study programs explicitly. We also uncovered that, at this moment, there is little guidance on how to establish interdisciplinary SSC study programs. We failed to identify such guidance within the information technology, public administration, public management or urban management literature, in line with [31], [33]. Moreover, the variety of study fields indicates the lack of a universal definition of SSCs used by universities or city administrations [3], [23]. Overall, we confirm that the SSC study programs have not become an educational standard yet [31] and that there is a need for a framework that integrates urban administration, smartness and sustainability with SSC programs.

Third, one of the main distinguishing features of our study is the fact that the analyzed programs reflect the current offerings by HEIs at the bachelor, master and course levels. This provides a unique insight to the development of new SSC study programs: 1) when developing bachelor-level programs, it assures access to master-level competencies; 2) when developing master-level programs, it guarantees the provision of essential bachelor-level competencies to students who came to receive this degree from other fields of study; and 3) regardless of the types of study programs, the presence of online courses assures the coverage of the most popular areas and develops competencies that take into account current trends and market needs.

The main methodological contribution of this study is introducing guidance on SSC study program development. Since each cluster is built using an interdisciplinary approach, direct adoption is possible. Thus, we propose a systematic approach towards making new SSC study programs that guarantees both fields of study and interdisciplinary education [52].
This approach consists of the following steps: 1) develop a list of keywords that reflect the target field of study, objectives and content; 2) compare the field of study keywords to the cluster keywords in Table 1 to identify the target cluster; 3) get familiar with the knowledge area and skill categories in Tables 2 and 3;4) Based on the proportions of the knowledge area and skill categories of the target cluster in Figure 3, develop a tailored SSC study program structure; 5) join together the target field of study keywords and the cluster's keywords; 6) create new SSC study program objectives and content based on 4 and 5 .

\section{Conclusions}

Interdisciplinary teaching and learning that integrates the issues of sustainability, smartness and urbanization is imperative for any SSC workforce. This paper adds to existing literature the analysis of interdisciplinary in the current SSC education programs offered by HEIs at the bachelor, master and supplementary levels. The analysis uncovered a rich set of SSC study programs from around the world and a unique set of competencies - knowledge and skills delivered by such programs. The analysis also grouped the identified programs into major thematic clusters, and the identified competencies into categories and cognition levels according to Bloom's taxonomy. Correlation between categories and the distribution of categories across clusters were also analyzed, providing additional insights into the findings.

The limitations of this research include a limited number of study programs analyzed, unequal coverage of the areas of knowledge and categories of skills in the identified program sample, and the reliance of the findings and insights on the sample.

Future research includes: analyzing a mismatch between SSC education offerings and the demand for SSC education captured by vacancy announcements; in-depth qualitative analysis of the study programs; and the development of a competency framework to contribute to foundation-building for SSC to become a professional, research and teaching discipline.

\section{Acknowledgements}

The authors wish to thank Karolina Krause-Brykalska and Katarzyna Ossowska for the input in this study. This research was partially supported by the Erasmus+ Programme of the European Union, project reference number 598273-EPP-1-2018-1-AT-EPPKA2-CBHEJP. 


\section{References}

[1] J. Ahern, S. Cilliers, and J. Niemelä, "The concept of ecosystem services in adaptive urban planning and design: A framework for supporting innovation," Landsc. Urban Plan., vol. 125, pp. 254-259, 2014.

[2] X. Q. Zhang, "The trends, promises and challenges of urbanisation in the world," Habitat Int., vol. 54, pp. 241-252, May 2016.

[3] M. Höjer and J. Wangel, "Smart sustainable cities: Definition and challenges," Adv. Intell. Syst. Comput., vol. 310, pp. 333-349, 2014.

[4] G. V. Pereira, E. Estevez, R. Krimmer, M. Janssen, and T. Janowski, "Towards a smart sustainable city roadmap," in ACM International Conference Proceeding Series, 2019, pp. 527-528.

[5] G. V. Pereira, P. Parycek, E. Falco, and R. Kleinhans, "Smart governance in the context of smart cities: A literature review," Information Polity, vol. 23, no. 2. IOS Press, pp. 143-162, 2018.

[6] A. Knol, M. Janssen, and H. Sol, “A decision enhancement service for stakeholder analysis to achieve transformations in the public sector," in Proceedings of the Annual Hawaii International Conference on System Sciences, 2015, vol. 2015March, pp. 2466-2475.

[7] O. Agbabiaka and A. Ojo, "Framework for assessing institutional readiness of government organisations to deliver open, collaborative and participatory services," in ACM International Conference Proceeding Series, 2014, vol. 2014January, pp. 186-189.

[8] J. Bertot, E. Estevez, and T. Janowski, "Universal and contextualized public services: Digital public service innovation framework," Government Information Quarterly, vol. 33, no. 2. Elsevier Ltd, pp. 211-222, 01-Apr-2016.

[9] T. Janowski, E. Estevez, and A. Ojo, "Conceptualizing Electronic Governance education," in Proceedings of the Annual Hawaii International Conference on System Sciences, 2012, pp. 2269-2278.

[10] F. V. Michelucci, A. De Marco, and A. Tanda, "Defining the Role of the Smart-City Manager: An Analysis of Responsibilities and Skills," J. Urban Technol., vol. 23, no. 3, pp. 23-42, Jul. 2016.

[11] Estevez Elsa, Nuno L., and Janowski Tomasz, "Smart Sustainable Cities Reconnaissance Study," 2016.

[12] S. E. Bibri, Smart Sustainable Cities of the Future.

[13] S. E. Bibri and J. Krogstie, "ICT of the new wave of computing for sustainable urban forms: Their big data and context-aware augmented typologies and design concepts," Sustain. Cities Soc., vol. 32, pp. 449-474, Jul. 2017.

[14] M. Batty et al., "Smart cities of the future," Eur. Phys. J. Spec. Top., vol. 214, no. 1, pp. 481-518, Dec. 2012.
[15] M. Batty, "Big data, smart cities and city planning.," Dialogues Hum. Geogr., vol. 3, no. 3, pp. 274-279, Nov. 2013.

[16] D. Kyriazis, T. Varvarigou, D. White, A. Rossi, and J. Cooper, "Sustainable smart city IoT applications: Heat and electricity management \& Eco-conscious cruise control for public transportation," in 2013 IEEE 14th International Symposium on a World of Wireless, Mobile and Multimedia Networks, WoWMoM 2013, 2013.

[17] L. Morinière, "Environmentally influenced urbanisation: footprints bound for town?," Urban Stud., vol. 49, no. 2, pp. 435-50, Feb. 2012.

[18] "Smart Cities How rapid advances in technology are reshaping our economy and society," 2015.

[19] A. Wyckmans and A. H. Wiberg, "Industry- and research-driven education in sustainable architecture: Transitioning towards a professional M.Sc. programme on zero emission built environments," Int. J. Sustain. Build. Technol. Urban Dev., vol. 2, no. 4, pp. 267-275, 2011.

[20] A. Wiek, L. Withycombe, and C. L. Redman, "Key competencies in sustainability: A reference framework for academic program development," Sustainability Science, vol. 6, no. 2. pp. 203-218, Jul-2011.

[21] S. Vincent and W. Focht, "Interdisciplinary environmental education: Elements of field identity and curriculum design," J. Environ. Stud. Sci., vol. 1, no. 1, pp. 14-35, 2011.

[22] E. R. Osagie, R. Wesselink, V. Blok, T. Lans, and M. Mulder, "Individual Competencies for Corporate Social Responsibility: A Literature and Practice Perspective," J. Bus. Ethics, vol. 135, no. 2, pp. 233-252, 2016.

[23] S. E. Bibri, "A foundational framework for smart sustainable city development: Theoretical, disciplinary, and discursive dimensions and their synergies," Sustain. Cities Soc., vol. 38, pp. 758794, Apr. 2018.

[24] B. S. Bloom, Taxonomy of educational objectives: The classification of educational goals. New York: Longmans, Green, 1956.

[25] L. W. Anderson and D. R. Krathwol, A taxonomy for teaching, learning, and assessing: A revision of Bloom's taxonomy of educational objectives. New York: Longman, 2001.

[26] B. Mansfiled, "What is 'competence' all about?," Competency, vol. 6, no. 3, 1999.

[27] R. Boyatzis, The Competent Manager: A Model for Effective Performance. New York: John Wiley \& Sons, Ltd, 1982.

[28] WG Spady, Outcome-based education: critical issues and answers. Arlington: American Association of School Administrators, 1994.

[29] L. K. J. Baartman, T. J. Bastiaens, P. A. Kirschner, and C. P. M. van der Vleuten, "Evaluating assessment quality in competence-based education: A qualitative comparison of two frameworks," Educ. Res. Rev., vol. 2, no. 2, pp. 114-129, Jan. 2007. 
[30] R. W. Scholz, D. J. Lang, A. Wiek, A. I. Walter, and M. Stauffacher, "Transdisciplinary case studies as a means of sustainability learning: Historical framework and theory," Int. J. Sustain. High. Educ., vol. 7, no. 3, pp. 226-251, Jul. 2006.

[31] D. O'Byrne, W. Dripps, and K. A. Nicholas, "Teaching and learning sustainability: An assessment of the curriculum content and structure of sustainability degree programs in higher education," Sustain. Sci., vol. 10, no. 1, pp. 43-59, Jan. 2015.

[32] E. Staniškiene and Z. Stankeviciute, "The Integration of Competencies for Sustainable Development: A Case of Study Programmes in a Non-elite University," in Universities as Living Labs for Sustainable Development, World Sust., L. F. et al. W, Ed. Springer, 2020, pp. 589-604.

[33] Y. Mochizuki and Z. Fadeeva, "Competences for sustainable development and sustainability: Significance and challenges for ESD," Int. J. Sustain. High. Educ., vol. 11, no. 4, pp. 391-403, 2010.

[34] M. Barth, J. Godemann, M. Rieckmann, and U. Stoltenberg, "Developing key competencies for sustainable development in higher education," Int. J. Sustain. High. Educ., vol. 8, no. 4, pp. 416-430, 2007.

[35] D. S. Oh, "Building Inter-Personal Competence in Architecture and Urban Design Students through Smart Cities at a Higher Education Institution," Sustainability, vol. 11, no. 24, p. 7179, Dec. 2019.

[36] J. Cusick, "Study abroad in support of education for sustainability: A New Zealand case study," Environ. Dev. Sustain., vol. 11, no. 4, pp. 801813, Aug. 2009.

[37] UNESCO, "Shaping the Future We Want. UN Decade of Eduation for Sustainable Development (2005-2014)," Paris, 2014.

[38] B. Van Horen, M. Leaf, and S. Pinnawala, "Localizing a global discipline: Designing new planning programs in Sri Lanka," J. Plan. Educ. Res., vol. 23, no. 3, pp. 255-268, 2004.

[39] E. Estevez and T. Janowski, "Landscaping Government Chief Information Officer education," in Proceedings of the Annual Hawaii International Conference on System Sciences, 2013, pp. 1684-1693.

[40] J. J. Salovaara, K. Soini, and J. Pietikäinen, "Sustainability science in education: analysis of master's programmes' curricula," Sustain. Sci., vol. 15, no. 3, pp. 901-915, May 2020.

[41] P. Biberhofer and C. Rammel, "Transdisciplinary learning and teaching as answers to urban sustainability challenges," Int. J. Sustain. High. Educ., vol. 18, no. 1, pp. 63-83, 2017.

[42] W. Lambrechts, C. J. Gelderman, J. Semeijn, and E. Verhoeven, "The role of individual sustainability competences in eco-design building projects," J. Clean. Prod., vol. 208, pp. 16311641, Jan. 2019.

[43] W. Lambrechts, I. Mulà, K. Ceulemans, I.
Molderez, and V. Gaeremynck, "The integration of competences for sustainable development in higher education: An analysis of bachelor programs in management," in Journal of Cleaner Production, 2013, vol. 48, pp. 65-73.

[44] D. Grimaldi and V. Fernandez, "The alignment of University curricula with the building of a Smart City: A case study from Barcelona," Technol. Forecast. Soc. Change, vol. 123, pp. 298-306, Oct. 2017.

[45] N.E. Tshikwatamba, "Critical and interdisciplinary analyses of the selected criticism leveled against public administration," 2007.

[46] Steph Menken and Machiel Keestra, An Introduction to Interdisciplinary Research. .

[47] J. Godemann, "Promotion of interdisciplinary competence as a challenge for Higher Education," vol. 5, no. 2, pp. 51-61, 2006.

[48] S. F. Akkerman and A. Bakker, "Boundary crossing and boundary objects," Review of Educational Research, vol. 81, no. 2. pp. 132-169, Jun-2011.

[49] J. F. Almasi, "Crossing Boundaries in Literacy Research: Challenges and Opportunities," Lit. Res. Theory, Method, Pract., vol. 65, no. 1, pp. 24-46, 2016.

[50] J. C. K. Lam, R. M. Walker, and P. Hills, "Interdisciplinarity in sustainability studies: A Review," Sustain. Dev., vol. 22, no. 3, pp. 158176, 2014.

[51] E. Mazur, "Key-note Address UTwente 25th of October 2015. Tour de Mazur in the Netherlands." 2015.

[52] Y. Chen, T. A. Daamen, E. W. T. M. Heurkens, and W. J. Verheul, "Interdisciplinary and experiential learning in urban development management education," Int. J. Technol. Des. Educ., 2019.

[53] A. H. Whittemore, "Practitioners Theorize, Too: Reaffirming Planning Theory in a Survey of Practitioners' Theories," J. Plan. Educ. Res., vol. 35, no. 1, pp. 76-85, Mar. 2015.

[54] A. S. Johnston, "City section: A pedagogy for interdisciplinary research and collaboration in planning and environmental design," J. Plan. Educ. Res., vol. 15, no. 1, pp. 86-92, 2015. 